\title{
Regulations and practices of genetic counselling in 38 European countries: the perspective of national representatives
}

\author{
Elina Rantanen*,1, Marja Hietala ${ }^{1}$, Ulf Kristoffersson ${ }^{2}$, Irmgard Nippert $^{3}$, Jörg Schmidtke ${ }^{4}$, \\ Jorge Sequeiros $^{5,6}$ and Helena Kääriäinen ${ }^{1,7}$
}

\begin{abstract}
${ }^{1}$ Department of Medical Genetics, University of Turku, Turku, Finland; ${ }^{2}$ Department of Clinical Genetics, University Hospital of Lund, Lund, Sweden; ${ }^{3}$ Women's Health Research, Muenster Medical School, Muenster, Germany; Institute of Human Genetics, Hannover Medical School, Hannover, Germany; ${ }^{5}$ Instituto de Ciências Biomédicas de Abel Salazar, University of Porto, Porto, Portugal; ${ }^{6}$ Instituto de Biologia Molecular e Celular, University of Porto, Porto, Portugal;

${ }^{7}$ National Public Health Institute, Helsinki, Finland
\end{abstract}

The aim of this article is to review the national regulations and practices of genetic counselling in 38 European countries, and to examine how well they intersect the ideals of genetic counselling defined in international guidelines. Using an electronic survey, representatives of the National Societies of Human Genetics in 29 countries, and appropriate contact persons for the field of genetic counselling in 9 other countries, were asked about the regulations and practices. The answers showed that consent, confidentiality, genetic counselling in the context of prenatal diagnosis, those professionals who may perform genetic counselling, and non-directiveness were the topics most often either agreed upon among professionals or regulated in those countries. These are also among the key aspects of ideal genetic counselling, based on international guidelines. Counselling in the context of susceptibility testing for multifactorial diseases, counselling people from ethnic minorities and recontacting the counsellees, on the contrary, were topics regulated or guided by generally applied practices in only few countries. Many of the answers expressed a desire for more regulation of genetic counselling, and that more uniform practices of education and organization of genetic counselling would be welcome in Europe.

European Journal of Human Genetics (2008) 16, 1208-1216; doi:10.1038/ejhg.2008.93; published online 14 May 2008

Keywords: genetic testing; genetic counselling; national regulation; national practices

\section{Introduction}

As genetic testing has become more common, ever more international recommendations and guidelines have been written to guide and regulate the practices of genetic counselling. ${ }^{1}$ Because of the manifold situations faced in genetic counselling, it has been seen as important to

*Correspondence: E Rantanen, Department of Medical Genetics, University of Turku, Kiinamyllynkatu 10, Turku 20520, Finland.

Tel: + 3582333 7250; Fax: + 35823337300 ;

E-mail: elina.rantanen@utu.fi

Received 18 December 2007; revised 7 April 2008; accepted 9 April 2008; published online 14 May 2008 consider how it is defined and what aspects need to be covered in a counselling session. ${ }^{2}$ As the ideals of genetic counselling, set in international guidelines, are rather strong and uniform, ${ }^{3}$ it is important to know how they are put into practice in the national regulations and practices of genetic counselling.

In international guidelines, an ideal counselling session is seen as requiring an appropriately trained professional, who understands genetics and its ethical implications well, providing relevant and objective information, promoting its understanding by the patient, offering proper psychological support, respecting the confidentiality of genetic 
information, dealing adequately with the familial implications and potential discrimination, and ensuring informed consent and autonomous decision-making by the counsellee. ${ }^{3}$

Although these ideals are expressed rather uniformly in international guidelines, they may be read differently in different countries. According to the studies of Wertz and Fletcher ${ }^{4,5}$ autonomy of the counsellee, a nondirective approach, confidentiality, and the privacy of genetic information were emphasized considerably more in the English-speaking nations and in Western Europe than anywhere else.

Furthermore, the practices of genetic counselling have been shown to vary within and among the countries. The type of information and the manner in which it is provided have been observed to be far from standardized, and variation in the training of the providers of genetic counselling has been seen to lead to differences in the practices among countries. ${ }^{6}$ Although for example the Organisation for Economic Co-operation and Development guidelines for quality assurance of molecular genetic testing require the recognition of medical genetics as a discipline that comprises a clinical speciality, ${ }^{7}$ there are European countries where it is still not recognized, and where there are few physicians trained in the field. ${ }^{8}$

There may be differences even within countries. Counselling best practices have been stated to be in use in the main genetics centres, but not all centres in the same country operate in the same manner. ${ }^{1}$ There are also many laboratories that do not have direct links to genetic counselling services, although such services should not be separated from the testing procedure. ${ }^{8}$ In some countries, there are also local factors that limit access to genetic services, such as geographical barriers, religion, health service setting, history of genetics, or lack of understanding of genetics by non-geneticists. ${ }^{9}$

Genetic testing is regulated through legislation in some European countries, ${ }^{1,10}$ but counselling associated with it is covered in only a few; ${ }^{11}$ some practices related to counselling, such as asking for consent and confidentiality of information, may be regulated in more general legislation related to health care. National professional and ethical guidelines also address different issues of genetic testing, sometimes including counselling. ${ }^{12}$ In addition, it can be expected that there are some generally applied practices of genetic counselling among professionals within some of the countries.

All of these three sources of guidance - the law, written professional guidelines and generally applied practices affect the way genetic counselling is practised. Although national legislation and guidelines concerning genetic testing have been listed, ${ }^{1,10,12}$ and there are databases ${ }^{13}$ that describe genetic testing practices in different countries, they rarely address topics specifically relating to genetic counselling. Therefore, the aim of this study was to review the national regulations and practices of genetic counselling in European countries from the perspective of their National Societies of Human Genetics (NSHG), and to examine how the existing practices live up to the ideals defined in international guidelines. It was also assumed that this kind of inter-country comparison might assist in the development of genetic service strategies in some countries.

\section{Methods}

Between September 2005 and February 2006, an electronic survey was performed in all European countries (except for Andorra, Liechtenstein, Monaco, San Marino, and the Vatican which were assumed to co-operate with their neighbouring countries in the field of genetic counselling). The NSHGs were assumed to have a general overview of the practices of genetic counselling in their country, and, thus, were selected as respondents. The questionnaire was sent to the president of the NSHG in the 29 European countries that had such a society. They were asked to have the questionnaire filled in within a group with experience in practical genetic counselling. All these societies provided their answers, written either by the board or the president of the society, or a designated expert. An appropriate contact person was sought with the assistance of the EuroGentest network and the European Society of Human Genetics in the countries found not to have a NSHG. The contact persons in nine additional countries answered the questionnaire. Thus, answers representing 38 countries were received (countries listed in Table 1). The survey was piloted in Finland and Belgium, and some small changes were made before it was sent to all countries.

Genetic counselling was defined for the respondents in a covering letter according to the definition of the European Society of Human Genetics. ${ }^{1}$ Questions about legislation, guidelines and generally applied practices of genetic counselling were formulated on the basis of the topics that came up in international guidelines for genetic counselling. ${ }^{3}$ By legislation, we mean official laws passed by the parliament or government, or any additional documents the respondents considered to be legally binding. By guidelines, we mean professional or other best practice recommendation papers. By generally applied practices, we refer to those that, though not necessarily written, are recognized as the common manners of practice.

Respondents were asked, whether their country had legislation, guidelines, or generally applied practices for counselling in different genetic testing situations. Testing situations that were asked about were counselling in the contexts of diagnostic, carrier, predictive, prenatal and pre-implantation testing, and susceptibility testing for multifactorial diseases. Next, the respondents were asked whether their countries had legislation, guidelines, or 
Table 1 Regulations and practices related to genetic counselling in 38 European countries according to the respondents

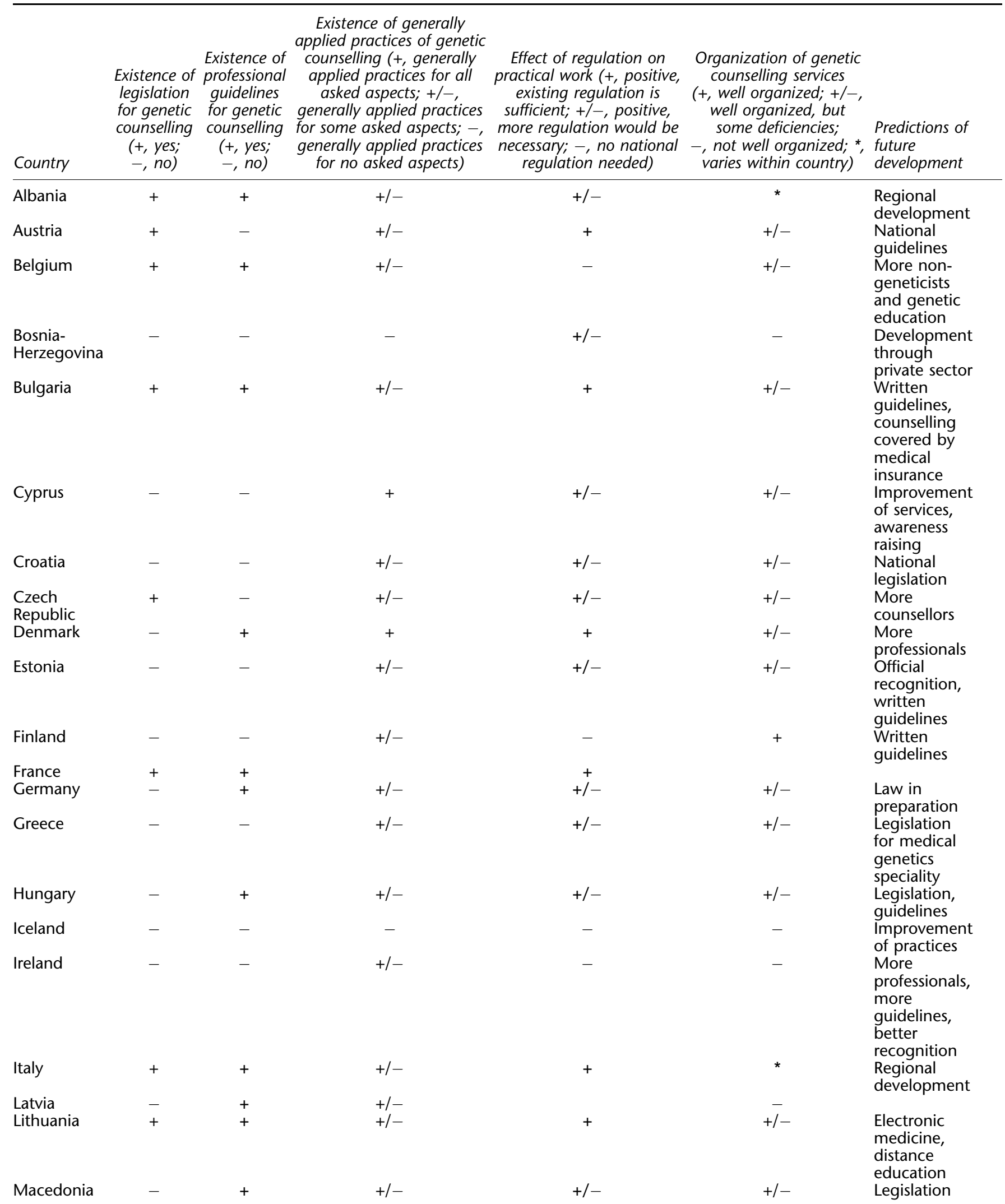


Table 1 (Continued)

\begin{tabular}{|c|c|c|c|c|c|c|}
\hline Country & $\begin{array}{c}\text { Existence of } \\
\text { legislation } \\
\text { for genetic } \\
\text { counselling } \\
\quad(+, \text { yes; } \\
-, \text { no) }\end{array}$ & $\begin{array}{l}\text { Existence of } \\
\text { professional } \\
\text { guidelines } \\
\text { for genetic } \\
\text { counselling } \\
\quad \text { (+, yes; } \\
\quad-, \text { no) }\end{array}$ & $\begin{array}{c}\text { Existence of generally } \\
\text { applied practices of genetic } \\
\text { counselling (+, generally } \\
\text { applied practices for all } \\
\text { asked aspects; +/-, } \\
\text { generally applied practices } \\
\text { for some asked aspects; -, } \\
\text { generally applied practices } \\
\text { for no asked aspects) }\end{array}$ & $\begin{array}{l}\text { Effect of regulation on } \\
\text { practical work }(+, \text { positive, } \\
\text { existing regulation is } \\
\text { sufficient; +1-, positive, } \\
\text { more regulation would be } \\
\text { necessary; }-, \text { no national } \\
\text { regulation needed) }\end{array}$ & $\begin{array}{l}\text { Organization of genetic } \\
\text { counselling services } \\
\text { (+, well organized; +/-, } \\
\text { well organized, but } \\
\text { some deficiencies; } \\
\text {-, not well organized; *, } \\
\text { varies within country) }\end{array}$ & $\begin{array}{l}\text { Predictions of } \\
\text { future } \\
\text { development }\end{array}$ \\
\hline Malta & - & - & - & $+/-$ & - & $\begin{array}{l}\text { Changes } \\
\text { with next } \\
\text { generation }\end{array}$ \\
\hline Moldova & + & - & $+1-$ & $+/-$ & $+1-$ & Legislation \\
\hline Netherlands & - & + & $+1-$ & - & + & $\begin{array}{l}\text { Common } \\
\text { cases into } \\
\text { regional } \\
\text { hospitals }\end{array}$ \\
\hline Norway & + & + & $+1-$ & + & $+/-$ & $\begin{array}{l}\text { Better } \\
\text { defined cases }\end{array}$ \\
\hline Poland & - & - & $+1-$ & $+/-$ & $+1-$ & $\begin{array}{l}\text { More } \\
\text { complex } \\
\text { disorders to } \\
\text { counselling }\end{array}$ \\
\hline Portugal & + & - & $+/-$ & + & $+/-$ & Legislation \\
\hline Romania & - & - & $+1-$ & - & - & $\begin{array}{l}\text { Improvement } \\
\text { of practices }\end{array}$ \\
\hline Russia & - & + & $+1-$ & + & - & $\begin{array}{l}\text { Pessimistic } \\
\text { predictions }\end{array}$ \\
\hline $\begin{array}{l}\text { Serbia and } \\
\text { Montenegro }\end{array}$ & - & - & $+/-$ & - & * & $\begin{array}{l}\text { Quality } \\
\text { assessment, } \\
\text { national } \\
\text { databases }\end{array}$ \\
\hline Slovakia & - & + & $+1-$ & + & $+/-$ & Legislation \\
\hline Slovenia & - & + & $+1-$ & - & * & $\begin{array}{l}\text { Legal and } \\
\text { professional } \\
\text { regulation }\end{array}$ \\
\hline Spain & - & - & $+1-$ & $+/-$ & - & $\begin{array}{l}\text { Formal } \\
\text { recognition }\end{array}$ \\
\hline Sweden & - & + & $+1-$ & - & $+1-$ & $\begin{array}{l}\text { Legal } \\
\text { regulation }\end{array}$ \\
\hline Switzerland & + & + & $+1-$ & + & - & $\begin{array}{l}\text { Hope for } \\
\text { non-deterioration }\end{array}$ \\
\hline Turkey & - & + & $+/-$ & $+/-$ & - & $\begin{array}{l}\text { Legislation for } \\
\text { medical } \\
\text { genetics } \\
\text { speciality }\end{array}$ \\
\hline UK & - & + & $+/-$ & - & + & $\begin{array}{l}\text { Complication } \\
\text { of patient } \\
\text { journey } \\
\text { through } \\
\text { genetic } \\
\text { service }\end{array}$ \\
\hline Ukraine & + & + & $+/-$ & $+/-$ & $+/-$ & $\begin{array}{l}\text { Improvement } \\
\text { of methods } \\
\text { and guidelines }\end{array}$ \\
\hline
\end{tabular}

generally applied practices for different aspects of genetic counselling. These aspects were: by whom counselling may be performed, asking for consent, confidentiality and the need to breach it, non-directiveness of counselling, offering psychological support to the counsellee, informing atrisk relatives, the duty to recontact the patient (which means the possible ethical or legal obligation of genetic service providers to recontact former patients about advances in research that might be relevant to them), counselling minors or those with diminished mental capacity, and counselling members of ethnic minorities. The answers are summarized in Table 1.

Respondents were also asked to describe how the existence or lack of legislation and guidelines affected the 
practical genetic counselling work, how well genetic counselling services were organized in their country, in their opinion, and how they predicted the situation would change in the coming years. These were open questions, but the answers could be classified into different categories. These are presented and summarized in Table 1. The questionnaire is accessible at: http://www.eurogentest.org/ cocoon/egtorg/web/info/questionnaire/unit3.xhtml.

Answers were compared to each other with the help of Statistical Package for Social Scientists, to gain an overall view of the regulations and practices of genetic counselling in Europe. This study, however, is not and does not aim to be a quantitative analysis of European practices, but a description of the situation from the perspective of a representative from each country.

\section{Results}

According to the survey, there are no legislation or professional guidelines specifically regulating genetic counselling in 13 European countries. In 9 countries, there are both legislation and guidelines, in 4 countries only legislation, and in 12 countries only guidelines. However, in most of the countries, there is more general health-care legislation or guidelines that affect genetic counselling, relating for example to confidentiality or patient rights. Respondents from 35 countries reported at least some generally applied practices of genetic counselling (Table 1).

\section{Counselling in the context of different testing situations}

Counselling in the context of prenatal testing was mentioned most often of all the situations listed in the enquiry as being covered both by legislation and national guidelines, and guided by a generally applied practice. Counselling in the context of diagnostic testing was the second most considered to be covered by regulations, and together with counselling in the context of carrier testing, it was regarded to be guided by generally applied practices as often as counselling in prenatal testing. Counselling in the context of susceptibility testing for multifactorial diseases was least often covered by legislation, guidelines, or generally applied practices (Figure 1).

In some of the countries that reported having generally applied practices, there were regulations guiding these practices. The respondents who described their generally applied practices explained that counselling takes place both before and after testing, or, in the context of diagnostic testing, sometimes only before or after a genetic test, as needed. Five respondents mentioned that counselling was performed only in appropriate settings, for example within clinical genetics services. In the context of predictive genetic testing, offering psychological support to the counsellee was also mentioned, as well as not performing such tests on children.

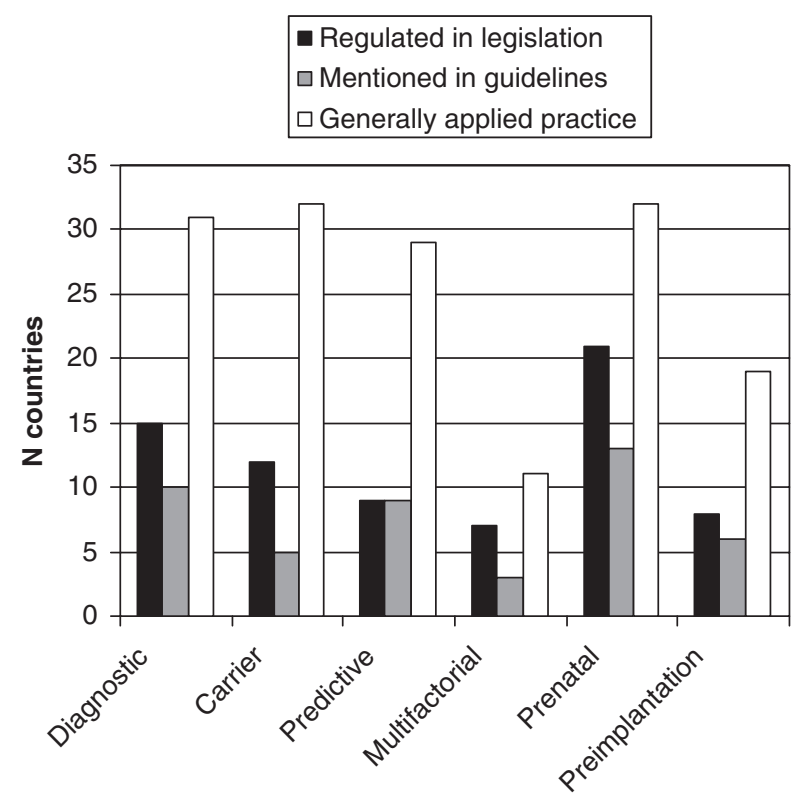

Figure 1 Genetic counselling associated with different testing situations regulated by legislation and guidelines and regarded as a generally applied practice in 38 European countries.

\section{Different aspects of genetic counselling}

The aspects relating to genetic counselling that the respondents mentioned their national legislation covered most often were informed consent and confidentiality. These were also mentioned in the answers from some of the countries with no specific legislation for genetic counselling; thus, consent and confidentiality are covered in many European countries by other laws regulating health care. Topics that were most often covered in the national professional guidelines were non-directiveness, confidentiality, and by whom genetic counselling may be provided (Figure 2).

Non-directiveness and the qualifications required to perform genetic counselling were also most often regarded as guided by generally applied practices (Figure 2). Some respondents mentioned these as being regulated in written guidelines. Respondents from 19 countries described that only specialized medical geneticists or genetic counsellors may perform genetic counselling, whereas eight respondents said that sometimes other medical professionals provide counselling as well. Representatives from six countries thought that the non-directiveness of genetic counselling is the golden rule in their country, but nine respondents felt that this applied only among professionals specialized in medical genetics.

Respondents from 26 countries considered that there is a generally applied practice of contacting relatives at risk in their country. Seven of them explained that the relatives are contacted only through the index patient, whereas another seven respondents mentioned that it is possible for the professional to contact the relatives directly, with the 


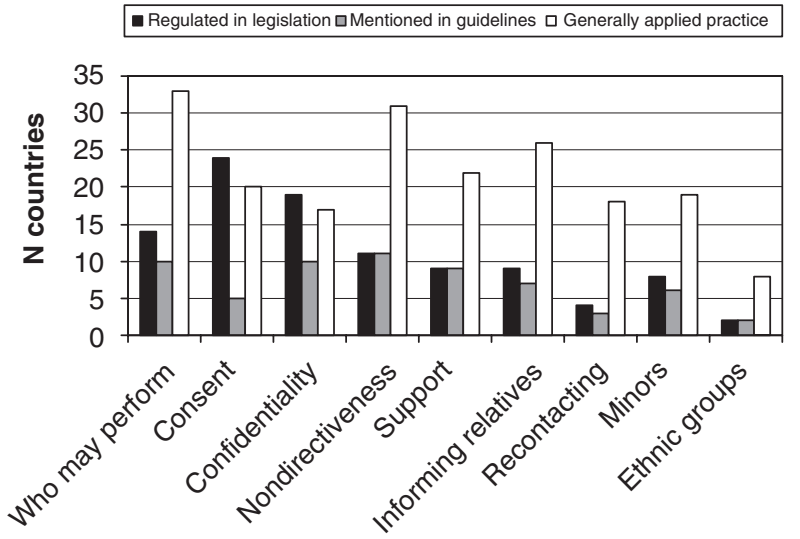

Figure 2 Issues related to genetic counselling regulated by legislation and guidelines and regarded as a generally applied practice in 38 European countries.

consent of the index patient. Respondents from 22 countries regarded offering psychological support in connection with counselling as a generally applied practice. Respondents from 19 countries thought that there are generally applied practices related to counselling of minors or persons with diminished mental capacity. Respondents from six countries mentioned the presence of parents, an appropriate level of counselling, and counselling in clinical genetics settings such as practices.

Respondents were specifically asked about the practice of asking for consent in different testing situations. Representatives of 20 countries said that there was a generally applied practice of asking for consent for every genetic test, whereas in 15 countries it was reported as being applied only for some testing situations. Half of these respondents answered that written consent is required for some cases, whereas in other cases only verbal consent is asked. Most often, written consent was required in the contexts of prenatal and predictive testing. In 12 countries, written consent was required for all types of genetic testing, whereas in 4 countries, verbal consent was always sufficient.

There were also topics that were seldom covered in national legislation and guidelines, or regarded as guided by a generally applied practice. These were, in particular, counselling individuals from ethnic minorities, and the duty to recontact the patient, and also breaching confidentiality (Figure 2). It was mentioned that recontacting occurs whenever possible. Only one representative mentioned that there are registers through which patients are contacted, if needed. Respondents from four countries said that breaching confidentiality is forbidden by the law or the guidelines, whereas another four mentioned that it is done only in exceptional cases and never without the consent of the patient. Only three respondents mentioned having generally applied practices related to counselling individuals from ethnic minorities. They described using interpreters and involving aspects of cultural differences in the training of professionals.

Respondents' assessment of regulation, current status, and future of genetic counselling in their country Respondents were asked how the existence or the lack of regulation affected the practice of counselling in their countries. Respondents from nine countries thought that the effect of the existing regulation was positive and were satisfied with the regulation they had. 'The existence of such legislation helps to standardize practical work', explained one respondent. Respondents from 18 countries wanted more or better regulation; for example, it was stated that 'national legislation should be more detailed' and that the lack of regulation had a negative effect 'due to different considerations among specialists and patients as well'. Respondents from 10 countries thought that national regulation was not necessary, even though five of them had legislation or some guidelines. 'Most guidelines which exist are helpful, but lack of legislation allows flexible practice', remarked one respondent. Some of these 10 respondents thought that there was no need for national guidelines, because 'the professional staff follows international guidelines'. Those respondents who wanted more regulation of genetic counselling came from all over Europe, but mostly from the new and candidate European Union (EU) member states, or from countries that are not involved in the EU (Table 1).

Respondents were asked to describe how well genetic counselling was organized in their country. Only respondents from three countries were completely satisfied with the situation. 'There is a good access throughout the country and there is a sufficient number of well-trained clinical geneticists', explained one. Most of the respondents were rather satisfied with their situation, but thought that some improvements were needed. Positive aspects that were mentioned were the access to and good infrastructure of counselling services, and a sufficient level of education and expertise. The gaps that were mentioned also related to educational and service provision issues. 'There is a lack of provision in relation to the demand on genetic counselling', commented one respondent. Fourteen respondents considered that genetic counselling was not at all optimal in their country. It was stated that genetic counselling was not at all organized, or that a lot of improvement was still needed. It was also said that there was a lack of specialists, a need for better education, failures in networking, and a lack of formal recognition of the field. In addition, representatives of four countries thought that the organization of counselling varied within the country. One explained that 'genetic counselling is well organized only in the capital'.

Respondents were provided with a list of factors, and asked to mark those they considered to create problems in the organization of genetic counselling in their country. 
More than 70\% marked the lack of general genetic knowledge among health-care professionals, and the prioritization of health-care resources; in addition, more than $60 \%$ referred to the lack of legislation and guidelines, and the lack of trained professionals to be such factors. Representatives from 10 countries thought that unequal access to counselling, sometimes related to geographical distances, was a problem. Only representatives from four countries considered that there were language and cultural problems in counselling. Outside the list, the reasons that were mentioned included the poor quality control of practices, lack of medical insurance, lack of corporate identity among geneticists, and problems specific to a small population.

Finally, respondents were asked to describe what their predictions were about the changes that might happen in genetic counselling practices in their countries in the near future. Even though this was an open question, 17 respondents predicted or hoped for more legally binding regulations or written professional guidelines. Some of these respondents described why this development is needed. 'The new legislation I hope will make the provision of medical genetic services more uniform all over the country', explained one. In some countries the changes were expected to formalize the position of medical genetics. It was also thought that genetics would be more integrated with other fields of health care, both in primary care and in other speciality fields such as oncology. An increase in the number of professionals in the field, general improvements, and regional development were also mentioned. Two respondents were afraid that there would be no development in genetic counselling in their country in the near future. Issues that only one respondent mentioned as a future development were improvements in the definition of cases that needed counselling, an increase in continuous training, and that development would take place only through the private sector, or when the next generation of physicians entered in the field. It was also predicted that the patient journey through the genetic service system would become more difficult.

\section{Discussion}

The aim of this study was to determine what regulations and practices of genetic counselling were in place in different European countries, and how they reflected the ideals of genetic counselling as defined in international guidelines. The legislative framework in different countries is important to know, but national guidelines, too, may have a considerable role in the regulation of counselling practices. It is also obvious that legislation may not be the best vehicle for addressing emerging topics (eg, susceptibility testing, recontacting patients, or counselling ethnic minorities), whereas professional guidelines may be more precise, their endorsement is faster, and they can be easily reviewed when new developments occur. They also reflect the ideals of genetic counselling better than legislation. It was known beforehand that in most of the countries there are no regulations specifically related to genetic counselling. ${ }^{11}$ Therefore, generally applied practices were also enquired upon. It can be assumed that at least in smaller countries, it is generally known or even agreed how issues related to counselling are managed.

However, the questions about legislation, guidelines, and generally applied practices were difficult both to formulate and to answer. Some of the respondents may not have known about every guideline in their country. There may be legislation on different levels, and some of the respondents may have included more general health-care legislation, whereas the others focused only on genetics. Some of the respondents answered more generally about genetic testing and did not focus on counselling. Therefore, the answers are not completely comparable. Some descriptions may also reflect the opinions of only one person, although the request was that the respondents would answer from a more general perspective. In addition, respondents probably based their evaluations of genetic counselling services on the general level of wealth and health care in their country, and thus, the answers cannot be regarded as absolutely corresponding between the countries. It is also possible that some NSHGs may not have been fully informed about all the practices of genetic counselling in their country.

In spite of these shortcomings, the answers still highlight the key issues in the current regulations and practices of genetic counselling. It seems that counselling in the context of prenatal diagnosis is quite often regulated both in the legislation and in the guidelines. In addition, the issues of informed consent, confidentiality, who may provide counselling, and non-directiveness are brought out in many guidelines and legally binding regulations. These same issues appear to be part of generally applied practices in most countries. In addition, counselling in the contexts of diagnostic and carrier testing were also often mentioned. Thus, it can be said that these situations and topics are both well discussed and regulated in many countries.

The most often regulated and agreed upon practices are also among the key ideals of genetic counselling emerging from international guidelines. ${ }^{3}$ There is a common opinion in these guidelines that the person who provides genetic counselling should be appropriately qualified, and that confidentiality should be respected, and consent should always be demanded. Non-directiveness relates to the autonomous decision-making of the patient, which is also expected in the international guidelines. These ideals are seemingly well applied in many European countries. Consent and confidentiality are well-applied principles in the countries at least because of their relevance for all 
medical interventions. ${ }^{14}$ Non-directiveness appears in the answers probably because it has served as a central ethos for genetic counselling for decades, providing both practical and ethical guidance to counsellors. ${ }^{15,16}$ Appropriate education of the professionals who provide genetic counselling emphasizes the exceptional nature of genetics in medicine, which has been discussed widely. ${ }^{17}$

Issues mentioned less often in the legislation were counselling people from ethnic minorities and the duty to recontact the patient after new developments, such as new therapies. ${ }^{18}$ These topics, as well as counselling in the context of susceptibility testing for multifactorial diseases, were seldom mentioned in guidelines. Exactly the same issues were also seen as the least guided by generally applied practices. These issues seem to be more difficult to regulate, newer topics in the discussion, or seen as less important than other topics.

In this respect, counselling in the context of susceptibility testing for multifactorial diseases, counselling individuals from ethnic minorities, and the duty to recontact former counsellees are issues that need further discussion as they are issues of growing importance, and there are few generally applied practices and regulations related to them according to this survey in Europe. It has been seen that large-scale immigration among and into European countries may place new demands on genetic services as there will be new genetic conditions and sociocultural issues surrounding counselling, treatment, and prevention. ${ }^{1,8}$ In addition, susceptibility testing for multifactorial diseases has been estimated to create potentially the biggest future demand for genetic testing services; ${ }^{8}$ although there have been critical visions of its importance, ${ }^{17}$ there have also been even more expectant perspectives $^{19,20}$ towards prediction in complex diseases. However, the need for information or genetic counselling when testing multifactorial diseases has not been discussed in depth. The duty to recontact the patient has inspired wide discussion, ${ }^{21,22}$ and it can be seen as becoming increasingly important as some of the information received in genetic counselling may become outdated. ${ }^{1}$

In this survey, in concordance with earlier studies, ${ }^{1,8}$ it became evident that the organization of genetic counselling and the sufficiency of clinical geneticists vary among (and even within) countries. Countries are different also due to their geographical barriers, population size, structure, and culture, which affect the organization of genetic counselling. As pointed out before, ${ }^{9}$ the lack of understanding of genetics by non-geneticists was also seen as a key obstacle when developing genetic counselling.

The existence of regulations and practices for genetic counselling varied among countries without any evident geographical or political pattern. However, many of the respondents who were satisfied with existing national regulation and with the organization of genetic counselling, came from the older EU member states, whereas the majority of the respondents who wanted more regulation, and who were less satisfied with genetic counselling in their country, came from the new and candidate EU member states, or from European countries not involved in the EU. According to an international study, ${ }^{4}$ different aspects of genetic counselling often mentioned in international guidelines, such as nondirectiveness and privacy, are given more emphasis in English-speaking nations and in Western Europe than elsewhere. International guidelines and recommendations may, thus, be less familiar in other European countries, possibly explaining why the respondents from those countries are hoping for more national regulation.

\section{Conclusions}

Answers provided by the European NSHGs on regulation and practices of genetic counselling in their respective countries highlighted the current key issues all over Europe. They showed that issues such as counselling in the context of prenatal diagnosis, who may perform genetic counselling, consent, confidentiality, and nondirectiveness, are the topics most often discussed and regulated. These aspects are strongly attached also to the ideal genetic counselling, as defined by international guidelines. Counselling in the context of susceptibility testing, counselling individuals from ethnic minorities, and recontacting the former patient are topics that particularly need more attention in the future as they are not regulated or regarded as guided by generally applied practices in most European countries, and as their significance is expected to be growing in the near future.

According to this survey, a greater emphasis is expected in the quantity and quality of education of professionals who provide genetic counselling, and in a more effective regulation of practices of genetic counselling. More regulation is expected, particularly in those countries that previous studies ${ }^{4}$ have shown to put less emphasis on some of the ideals set in international guidelines. More education was particularly desired for non-geneticist health-care professionals, who are expected to have a more pronounced role in medical genetics in the coming years.

\section{Acknowledgements}

This work was supported by EuroGentest, an EU-FP6 supported NoE contract number 512148. ER thanks her supervisors Harri Melin and Seppo Pöntinen at the Department of Sociology, University of Turku, Finland.

\section{References}

1 Godard B, Kääriäinen H, Kristoffersson U, Tranebjaerg L, Coviello D, Aymé S: Provision of genetic services in Europe: current practices and issues. Eur J Hum Genet 2003; 11 (Suppl 2): 13-48. 
2 Resta R, Bowles Biesecker B, Bennett RL et al: A new definition of genetic counseling: National Society of Genetic Counselors' Task Force Report. J Genet Couns 2006; 15: 77-83.

3 Rantanen E, Hietala M, Kristoffersson U et al: What is ideal genetic counselling? A survey of current international guidelines. Eur J Hum Genet 2008; 16: 445-452.

4 Wertz DC, Fletcher JC: Genetics and Ethics in Global Perspective. Dordrecht: Kluwer Academic Publishers, 2004.

5 Wertz DC, Fletcher JC: Attitudes of genetic counselors: a multinational survey. Am J Hum Genet 1988; 42: 592-600.

6 Bowles Biesecker B, Marteau TM: The future of genetic counselling: an international perspective. Nat Genet 1999; 22: $133-137$.

7 OECD: Guidelines for Quality Assurance in Molecular Genetic Testing. OECD: Paris, 2007.

8 Ibarreta D, Bock A, Klein C, Rodriguez-Cerezo E: Towards Quality Assurance and Harmonisation of Genetic Testing Services in the EU. European Commission Joint Research Centre: Seville, 2003.

9 Harris R: Genetic services in Europe. A Comparative Study of 31 Countries by the Concerted Action on Genetic Services in Europe. Eur J Hum Genet 1997; 5 (Suppl 2): 1-220.

10 Matthiessen-Guyader L: Survey on National Legislation and Activities in the Field of Genetic Testing in EU Member States. European Commission Directorate General: Research: Brussels, 2005.

11 Soini S: National regulation of genetic counselling. Published on EuroGentest website〈http://www.eurogentest.org/web/info/ public/unit3/regulations.xhtml $\rangle 2006$.
12 Borry P, Nys H, Goffing T, Dierickx K: Genetic testing and counselling. European Guidance. European Ethical-Legal Papers No 3. Leuven, 2007.

13 Orphanet 〈http://www.orpha.net $\rangle$.

14 World Medical Association: Declaration on the Rights of the Patient. Lisbon, Portugal: World Medical Assembly, 1981.

15 Clarke AJ: The process of genetic counselling. Beyond nondirectiveness; in Harper, PS, Clarke, AJ (eds).: Genetics, Society and Clinical Practice. Oxford: BIOS Scientific Publishers, 1997, pp 179-200.

16 Weil J: Psychosocial genetic counseling in the post-nondirective era: a point of view. J Genet Couns 2003; 12: 199-211.

17 Green MJ, Botkin JR: Genetic exceptionalism in medicine: clarifying the differences between genetic and nongenetic tests. Ann Intern Med 2003; 138: 571-575.

18 Vineis P, Schulte P, McMichael AJ: Misconceptions about the use of genetic tests in populations. Lancet 2001; 357: 709-712.

19 Evans JP, Skrzynia C, Burke W: The complexities of predictive genetic testing. BMJ 2001; 322: 1052-1056.

20 Yang Q, Khoury MJ, Botto L, Friedman JM, Flanders WD: Improving the prediction of complex diseases by testing for multiple disease-susceptibility genes. Am J Hum Genet 2003; 72: 636-649.

21 Letendre M, Godard B: Expanding the physician's duty of care: a duty to recontact? Med Law 2004; 23: 531-539.

22 Hunter AGW, Sharpe N, Mullen M, Meschino WS: Ethical, legal, and practical concerns about recontacting patients to inform them of new information: the case in medical genetics. Am J Med Genet 2001; 103: 265-276. 